\title{
Cómo se escribe una historia cultural: Madrid, 1900-1936*
}

\author{
EDWAR BAKER \\ Historiador de la Cultura e Hispanista
}

Muchas gracias a todos, al profesor Pérez Reyes por su amable presentación y al profesor Pérez Segura por haberme dispensado el honor de dirigirles a ustedes la palabra. Voy a plantear una serie de problemas que tienen un fondo estrictamente empírico, pero que en no pocos casos plantean problemas de tipo metodológico relacionados con la Historia cultural de la ciudad en el mundo contemporáneo, todo ello en el marco del Madrid prebélico. Voy a llamar la atención así mismo sobre lo que no acabamos de saber demasiado bien, que es mucho, y esto por una razón eminentemente práctica, porque en este momento estoy dando los primeros, o quizás los segundos pasos, hacia una Historia cultural de esta ciudad entre 1900 y 1936, porque en el otro proyecto, la Historia cultural de Madrid de Felipe II al año 2000 que yo coordino, somos siete, posiblemente ocho; yo no me atrevería a hacer en solitario esa proeza. Entonces, estoy dando esos pasos hacia una Historia cultural de esta ciudad entre 1900 y 1936 y es mucho, mucho, lo que no acabo de saber demasiado bien.

En 1920, Manuel Azaña escribió una serie de artículos sobre Madrid en La Pluma, revista que había fundado al alimón con un íntimo amigo que iba ser nueve años más adelante su cuñado, Cipriano Rivas Cherif. En el primero de esos artículos, hizo una observación que todos conocemos perfectamente y que desde entonces, y han pasado noventa y dos años, no ha dejado de levan-

\footnotetext{
* Transcripción revisada y actualizada de la conferencia inaugural de las V Jornadas Internacionales Arte y Ciudad. Madrid, Universidad Complutense, 21 de noviembre de 2012.
} 
tar ronchas en la piel de no pocos madrileños. Madrid -escribe Azaña- es un poblachón mal construido en el que se esboza una gran capital. En otro momento, en un libro sobre la Gran Vía madrileña en los años veinte y treinta, he argumentado que estas palabras reproducen a la perfección, con todas sus consecuciones y fracasos, el relato de modernización que los madrileños han traído entre ceja y ceja del siglo XIX a esta parte. Y aquel relato forma el marco dentro del cual voy a plantear los problemas a los que acabo de aludir, sometiendo a examen algunos tiempos y espacios de la ciudad y la cultura junto a las personas y las obras, y lo que hacen y dejan de hacer las personas con las obras en el contexto de los espacios y los tiempos.

Al emprender esta tarea voy a tomar como punto de partida un hecho demográfico y un tema relacionado con la economía y el Estado que hace unos años puso sobre el tapete un profesor de esta Facultad, José Carlos Rueda Laffond. Como en breve veremos, los dos temas tienen consecuencias decisivas para una Historia cultural de esta ciudad en las primeras décadas del siglo XX.

Vamos a empezar por la demografía. En 1900 había en el término municipal de Madrid, algo más de medio millón de habitantes, y digo "dentro del término municipal" porque a diferencia de otras ciudades como Barcelona o Bilbao, en cuyos respectivos cinturones industriales vivían centenares de miles de personas, esa cifra engloba la casi totalidad de la población madrileña, ya que es relativamente corto el número de habitantes de las inmediaciones en esos años. En 1935, año del último padrón municipal anterior a la guerra, había alrededor de un millón de madrileños. En esas tres décadas y media, la casi duplicación de la población tenía dos fuentes, relacionadas las dos con procesos de modernización: la emigración del campo a la ciudad por un lado y, por otro, los inicios de un proceso de crecimiento vegetativo positivo. He aquí una novedad histórica de una importancia absolutamente colosal. Entre 1920 y 1935 los padrones arrojan un saldo positivo de nacimientos frente a defunciones. Aquellas cifras eran producto de la mejora no necesariamente muy espectacular y siempre desigual, pero mejora paulatina de las condiciones materiales de vida sobre todo de las clases trabajadoras en todos los terrenos: higiene y sanidad, alimentación, vivienda, educación, trabajo, etc.

A ese millón de madrileños volveré, pero antes quiero comentar la observación que hizo el profesor Rueda Laffond hace cosa de veinte años. Desde el 
momento, 1561, en que Felipe II toma la determinación de transformar a Madrid en capital del reino, en capital de la monarquía española, existe un marcado desequilibrio entre Corte y Villa que influye poderosamente en la vida de todos los habitantes de la Villa. Hay, por un lado, un Estado prácticamente todopoderoso y, por otro, una ciudad más bien poco importante. En el orden político-militar, aquel Estado controla o pretende controlar medio mundo, pero al mismo tiempo la economía de la ciudad es en lo fundamental local y depende de la demanda que genera ese ejército de cortesanos y burócratas y esas órdenes religiosas que hacen a finales del siglo XVI lo que van a hacer los bancos, sobre todo la banca vasca, a fines del siglo XIX y comienzos del XX: arrimarse al poder.

Lo que observa Rueda Laffond en los aproximadamente veinticinco años anteriores a la guerra es que esa dualidad, que había formado el marco de la vida madrileña durante nada menos que tres siglos y medio, empezó a quedar superada con el surgimiento en la Restauración y la consolidación en las primeras décadas del siglo XX de una economía propiamente nacional, en la que en Madrid no es únicamente el Estado sino también la sociedad la que empezaba a crear una demanda de bienes y servicios de todo tipo, que ya no dependía rigurosamente del Estado, aunque éste seguía siendo, sin discusión alguna, un factor de primera importancia. Aquel viejo dualismo, la secular asimetría de Villa y Corte, entre Ciudad y Estado, empezaba a pertenecer al pasado.

Esa consolidación económica se produjo sobre todo a partir de la segunda década del siglo, momento de otras consolidaciones, empezando por la del movimiento obrero y al mismo tiempo de la nueva intelligentsia, que se hacía valer en el terreno de las letras, las ideas, el arte y la ciencia, en todo menos el poder político. Y este es un dato fundamental, porque en la segunda década se produjo la crisis del Estado que había diseñado Cánovas cuarenta años antes, un corsé institucional que ya no era capaz de controlar una sociedad en pleno proceso de expansión. Y esa crisis del Estado restauracionista se profundizó y transformó en una crisis de legitimidad que los españoles empezaron a superar tras la muerte de Franco en la madrugada del 20 de noviembre de 1975 y la paulatina implantación de un Estado de derecho.

Vamos a recuperar ahora a ese millón de madrileños que dejamos aparcados hace un momento y a la intelligentsia a la que acabo de aludir. A la hora 
de hacer una Historia de la cultura, la existencia de estos dos conjuntos nos permite, yo diría que nos obliga, elegir básicamente entre dos posibilidades, con sus consecuencias metodológicas. Podemos hacer una historia cultural protagonizada por las aproximadamente 200 personas que en 1900 constituyen la élite cultural de la capital de España, cifra que a la altura de 1936 había que duplicar, y probablemente más que duplicar. Si esos pocos centenares de personas son los sujetos privilegiados, por no decir casi únicos, de nuestra Historia, y muy bien podrían serlo, es porque eran creadores literarios y artísticos, generaban ideas, hacían ciencia y de una calidad excelsa en algunos casos, creaban editoriales, dirigían obras y diseñaban edificios, pintaban cuadros, hacían teatro y cine, y forjaban una compleja red de relaciones con el poder político, con el Estado. No cabe la menor duda que se puede hacer perfectamente una historia cultural cuyo fundamento sea el análisis descriptivo de las múltiples actividades de esas personas.

Todos sabemos quiénes eran. Partiendo de 1900, estaban Galdós, Valera, Menéndez y Pelayo, Giner, Cossío, Baroja, Azorín, Valle, Cajal, Marañón, Ortega, Menéndez Pidal, Zuloaga, Azaña, Morente, Secundino Zuazo, Torcuato Luca de Tena, Nicolás Urgoiti, Ramón Gómez de la Serna y Federico García Lorca, y José Moreno Villa, y Pedro Salinas, y Blas Cabrera, y Carmen de Burgos, y Luis Buñuel, y Salvador Dalí, y Maruja Mallo, y Miguel Hernández, y, y, y, y, y... los equis centenares de personas que con toda la razón del mundo protagonizarían nuestra Historia. Es más, yo tengo la certeza de que un libro elaborado con esa materia prima de lujo, sería verdaderamente fascinante porque aquellos personajes constituían en el Madrid de hace ochenta o noventa años nada menos que una nueva República de las Letras, tal y como se entendía en la Europa de los siglos XVII y XVIII esa expresión englobadora de lo mejor que es capaz de idear, sentir y realizar la cabeza y el espíritu del género humano. Esa moderna República de las Letras tenía una calidad y una coherencia extraordinarias y si alguien insiste a estas alturas en utilizar la expresión "Edad de Plata" con la que en los años sesenta mi maestro Juan Marichal bautizó la cultura española de toda la época, no me voy a oponer. Pero como cuestión de método, más que de etiquetas, debemos prestar una atención mucho más detallada a la formación histórica a lo largo de la Restauración de esa intelligentsia moderna y, sobre todo, a las instituciones públicas y privadas, muy imbricadas en muchos casos, que daban abrigo a su creatividad. 
Dicho todo esto, hay una segunda posibilidad que se puede plantear debido en parte a los hechos demográficos que expuse hace un momento. Esos hechos iban a tener consecuencias culturales importantes porque un número creciente de los que emigraban a la ciudad, de los que llevaban ya tres cuartos de siglo emigrando y, sobre todo, sus hijos y sus nietos que a la altura de 1920 sobrevivían porque se había elevado el nivel de vida, iban entrando en los círculos más amplios de la cultura urbana. Entonces, esa segunda posibilidad consiste en abordar las prácticas culturales de la población entera o al menos de un porcentaje muy elevado de la misma, porque si es innegable que nuestra Historia no es en absoluto factible sin el Ateneo, sin la Residencia, sin Revista de Occidente, sin el Centro de Estudios Históricos y una porción de cosas más, tampoco se puede hacer, yo al menos no la pienso hacer, de espaldas al $99 \%$ de los madrileños.

Ahora, si hemos de partir de la idea de que los sujetos de nuestra Historia son todos o casi todos los madrileños, debemos reconocer de entrada que no todos desempeñaban el mismo papel, y entonces nuestra primera obligación es deslindar y estructurar. Pero ¿estructurar qué cosas y cómo? Debemos buscar las respuestas, que en todo caso serían provisionales, en los tiempos y en los espacios de la producción y la circulación de los bienes de cultura, de todos los bienes de cultura, en el marco de una ciudad que en esos años evolucionaba con gran rapidez.

Vamos a partir de un hecho que en este caso atañe a los espacios. Desde que a raíz de la Guerra de Sucesión, una nueva dinastía tomó el poder hasta la creación hace dos días del Estado de las autonomías, se había ido implantando un modelo territorial centralizador. El centralismo es, ciertamente, lo único que tienen en común modelos estatales tan distintos entre sí como el absolutismo de los primeros Borbones, el Estado liberal, con la sola excepción de la Segunda República, y el franquismo. Aquel modelo centralizador se reprodujo en el Madrid contemporáneo, donde hace un siglo se decía proverbialmente, o no tan proverbialmente, que "para ir a cualquier lao hay que pasar por la Puerta del Sol". Idea o sentimiento reforzado por un sistema de transportes en el que el Metro y la casi totalidad de las líneas de tranvía construidas entre 1919 y 1936 convergían en ese kilómetro cero. A ese hecho es preciso agregar una observación fundamental que hizo hace cosa de veinte años Fernando de Terán: Madrid en la actualidad es una de las ciudades más 
compactas del mundo, y el Madrid histórico del casco y el ensanche lo era todavía más.

Vamos a ver, pero de forma muy somera, lo que a la altura de 1900 está ubicado en el casco: en el caserón de la calle de San Bernardo está la Universidad, que todavía en la época en que yo vine aquí a estudiar, año 1961, se llamaba Universidad Central; las Reales Academias, el Museo del Prado y la Biblioteca Nacional. En el otro extremo está el Palacio de Oriente, enfrente está el Teatro Real, y a poca distancia está el Senado. En el centro están las Cortes y los Ministerios, y si Presidencia, en Castellana 3, se separa del casco, la distancia es mínima. En la calle de Alcalá, entre Sol y Cibeles, entre Hacienda por un lado y el Banco de España por otro, están todos los grandes bancos, de origen vasco casi todos ellos. En el centro del centro, en Sol y sus inmediaciones, están las redacciones de muchos de los periódicos más importantes, los cafés y, por lo mismo, las tertulias de los escritores e intelectuales, y los teatros, amén de las tiendas más importantes. Y, a partir sobre todo de los años veinte, en el casco está la gran mayoría de los cines, aunque con algunas excepciones verdaderamente interesantes.

Y esto significa que los protagonistas de esa moderna República de las Letras se veían un día sí y otro también en múltiples puntos de encuentro, que eran otras tantas instituciones de cultura. Los productores de la misma, pertenecientes a la nueva República de las Letras, a esa intelligentsia moderna, se veían en esos espacios y podía haber entre ellos desacuerdos y hasta desavenencias, pero la proximidad de unos y otros a lo largo de varias décadas es innegable. Proximidad que incluye ciertamente a los que vivían en el ensanche que, a la altura de la República, tenía todavía algo de ciudad dormitorio desde el que acudían al casco lo mismo para trabajar que para gestionar asuntos relativos a la burocracia estatal, provincial o municipal, para comer y beber, para ir al teatro o al cine, para hacer compras de todo tipo que no fueran del día a día, en pocas palabras, para ir a esos puntos de encuentro que eran instituciones de la creación y la circulación cultural.

Ahora, en el casco no se encontraba exclusivamente la España oficial, la del Estado, de las Reales Academias, etcétera, porque al mismo tiempo abrigaba una población notablemente interclasista, y en aquel espacio compacto empezaba a producirse, como ha observado Ángel Bahamonde, un cierto aire mesocrático, 
consecuencia también de la subida del nivel de vida. Uno de los indicios más llamativos de esas mejoras materiales es el elevado número de madrileños que en esos años se alfabetizan y acceden a la lectura, y esto tiene unas consecuencias culturales que se visibilizaban a nivel de calle. Me refiero al quiosco, y una de mis asignaturas pendientes es la confección de un plano de los quioscos madrileños a la altura de 1930. En esos establecimientos callejeros no solamente se vendía prensa, sino una cantidad verdaderamente oceánica de impresos, sobre todo a unas personas pertenecientes a capas medias, medias bajas y trabajadoras, que rara vez pisaban una librería porque consideraban que era un territorio social y culturalmente ajeno a ellos. Había muchas decenas de miles de madrileños que a la hora de comprar lectura acudían al quiosco más próximo.

Esos nuevos impresos quiosqueros pueden dividirse fundamentalmente en dos, aunque hay una tercera categoría que comentaremos brevemente. En primer lugar estaban las colecciones semanales de novelas editadas en fascículos cuyo punto de arranque era en 1907 la que dirigía Eduardo Zamacois, El Cuento Semanal -todo un lujo por su gran formato, papel couché y sus cubiertas con caricaturas de los autores a todo color-. Enseguida, la colección lanzada por Zamacois tuvo competidores: La Novela Corta, Los Contemporáneos, El Cuento Teatral y, más adelante, El Cuento Cinematográfico, y un etcétera larguísimo. Estas colecciones en muchos casos, no en todos, reducían el formato, la calidad del papel y el precio, y en la tapa figuraba frecuentemente no la caricatura del autor sino la foto.

El nuevo formato hizo fortuna $\mathrm{y}$, a continuación, tuvo literalmente cien imitadores y una enorme oferta que incluía la novela sentimental de izquierdas, La Novela Ideal, cabecera de gran éxito perteneciente al pensador y escritor ácrata Federico Urales; y la novela sentimental de derechas, en que desarrolló una gran actividad, por poner un ejemplo, Pilar Millán Astray, hermana del general. Por lo demás estaba el género sicalíptico, capítulo importantísimo por su éxito de venta.

En segundo lugar, aunque solamente por razones de cronología, estaba la oleada de revistas semanales ilustradas pertenecientes en gran parte a la sociedad formada por Nicolás Urgoiti, Prensa Gráfica, cuyas cabeceras más importantes como La Esfera, Mundo Gráfico, etc., fueron una respuesta enormemente eficaz al surgimiento de nuevas hornadas de lectores cuya sensibilidad se 
estaba configurando en el contexto de la segunda y tercera décadas del siglo $X X$. De ahí el predominio de los reportajes fotográficos. Ahora, en esas formas de expresión, el gran predecesor fue Blanco y Negro, revista fundada por la empresa de Torcuato Luca de Tena, Prensa Española, en 1891, seguida del diario $A B C$, que en su número inicial del 1 de enero de 1903 llamaba la atención del lector a sus innovaciones en materia de formato y a la voluntad de ofrecer al público un contenido basado en la información gráfica. En la segunda década del siglo XX las revistas ilustradas de Urgoiti dieron un salto hacia adelante partiendo de lo que Prensa Española había creado, ampliando el material fotográfico y el público lector. Por lo demás, y es la tercera categoría de impresos quiosqueros importantes, no hay que olvidar la aparición en esas décadas del tebeo, principalmente en Barcelona pero con gran número de lectores, y no solamente infantiles, en Madrid y otras ciudades. Hay, por lo tanto, un momento en las décadas de entreguerras en que, como señala Alberto Sánchez Álvarez-Insúa, la lectura quiosquera era la forma más barata de ocio de una capa muy amplia de la población de Madrid y de toda España.

Al mismo tiempo, hay una literatura en parte quiosquera y en parte no, promovida por las formaciones políticas y sindicales del movimiento obrero: La Novela Roja, por ejemplo, y las bibliotecas populares, entre otras. Es un momento destacable que se relaciona con las escuelas promovidas por las agrupaciones socialistas y, sobre todo, los ateneos libertarios. Cabe señalar la importancia de la Biblioteca de la Casa del Pueblo, de inspiración socialista, con sus 4.000 volúmenes en la céntrica calle de Piamonte. Este hecho nos recuerda una vez más que había amplias zonas del casco que seguían siendo interclasistas en esos años y con una zonificación social vertical, típicamente decimonónica. Tenemos un cierto conocimiento del tema de la lectura popular gracias a los estudios, de gran calidad todos ellos, de Gonzalo Santonja en el caso de las colecciones literarias del movimiento obrero, de Alejando Tiana en el caso de la Biblioteca de la Casa del Pueblo y de la educación obrera de Madrid a comienzos de siglo, y de otros investigadores. Pero, sobre todo en el caso de los ateneos libertarios, necesitamos conocer estos temas mucho más a fondo, desde dentro y a pie de calle. Ahora, en cuanto a la lectura quiosquera en general, hacia 1920 constituía una de las condiciones de posibilidad de la implantación en España de una cultura de masas, al ser un fenómeno socialmente muy amplio de consumo de mercancías culturales. 
Pero la cultura de masas es un fenómeno cuantitativa y cualitativamente distinto, que se sostenía sobre los dos pilares del gran capital y las tecnologías de reproducción surgidas en el interior de la segunda Revolución Industrial. En Madrid, y sin extenderme mucho, el espacio privilegiado en esta nueva cultura de masas -el cinematógrafo, el gramófono, la radiofonía- era la Gran Vía. Quiero aludir brevemente a un fenómeno de gran importancia que todavía no se conoce a fondo: la entrada de esa cultura o de un aspecto determinado de ella en el espacio doméstico. Otro tema del que se sabe poco y se necesita saber más es la receptividad social ante la radio, tema del que sabemos relativamente poco y es un asunto que los investigadores necesitamos plantear de forma más sistemática. Sobre todo si aspiramos a hacer esa historia de la cultura de la preguerra protagonizada por la generalidad de los madrileños.

Si esa es nuestra meta, necesitamos abordar no solamente los espacios sino los tiempos de la cultura, empezando por el calendario. En las primeras décadas del siglo XX seguía rigiendo en toda España el calendario cristiano. Hubo múltiples intentos a lo largo del siglo XIX de secularizarlo y democratizarlo, intentos que a menudo reproducían los sentimientos y los gestos del calendario tradicional con la creación de santos laicos. A título de ejemplo veamos un calendario lanzado en 1869 al calor de la Septembrina que recoge figuras del pasado transformadas en mártires y defensores de la independencia y libertad de España. Con un propósito democratizador, pero sacralizando a la vez que pretendidamente desacralizaba, hacen acto de presencia las siguientes fechas con sus santos correspondientes:

- 25 de diciembre: San Emanuel Nazareno, natural de Belén, protomártir de la democracia universal;

- 23 de abril: 254 aniversario de la muerte del príncipe de los ingenios españoles, San Miguel de Cervantes Saavedra, natural de Alcalá de Henares;

- 2 de mayo: función cívica en honor de los mártires de la libertad e independencia española: Santos Pedro Velarde, Luis Daoiz y compañeros.

Yo no niego que a estas alturas resultan un poco cómicos y desde luego rechazables esos sincretismos culturales en que Miguel de Cervantes, Pedro Velarde y un largo etcétera se colocaban en los altares de los progresistas decimonónicos, pero sería conveniente no perder de vista que mi generación hizo lo propio con Antonio Machado, y si rechazamos así a rajatabla los 
sincretismos ya podemos acudir al trabajo durante el puente de la Inmaculada Constitución.

A lo que voy con todo esto es al hecho de que hay, a comienzos del siglo $X X$, una cultura popular en que los ocios secularizados, promovidos por las organizaciones sindicales, sobre todo en materia de deporte, excursiones y similares, y los espectáculos ofertados por la industria cultural de masas, convivían ampliamente con otros muchos ocios pertenecientes al calendario cristiano, empezando por los días de guardar y la cultura verbenera, que en Madrid tenía una importancia enorme. Durante mucho tiempo esa cultura verbenera ha sido monopolio de un cierto madrileñismo casticista con el que en alguna ocasión me he empleado con mucha dureza. Pero no debemos perder de vista que estamos ante un fenómeno cultural de gran importancia que necesitamos conocer mucho mejor y que tenemos que integrar de forma más coherente en el cuadro general de la cultura popular prebélica. He aquí un tema en que por ejemplo una antropología atenta a los espacios socioculturales nos puede ser de gran utilidad.

Con demasiada frecuencia hemos planteado los temas de la cultura popular - la tradicional católica, la proletaria, la de masas- como compartimentos estancos. Pensábamos que el trabajador afiliado a UGT que iba a la Biblioteca de la Casa del Pueblo a pedir prestado un folleto de Engels y una novela de Baroja no guardaba apenas relación con el católico perteneciente también a la clase trabajadora que iba a la Verbena de la Paloma. Pero el lector de Engels y Baroja también iba, y los dos compartían la misma casa de vecindad, y todos ellos se metían en el mismo cine de barrio alguna vez, y a lo mejor veían películas de inspiración casticista que igual les gustaban. O sea, que los diferentes terrenos del comportamiento cultural de las capas populares de Madrid podían ser algo más porosos de lo que parece a primera vista. Y perdonen que insista, pero aunque hemos avanzado algo, de esto todavía sabemos demasiado poco.

Ahora, la expansión demográfica, económica y cultural de esas décadas se desenvolvió en una ciudad en pleno crecimiento horizontal, pero también vertical. Vertical hacia arriba, con edificios de altura que rompieron por completo la escala de la ciudad, y también hacia abajo, porque el Metro, al poner a la clase trabajadora de Cuatro Caminos o Vallecas a 15 céntimos y 15 minutos de la Puerta del Sol, cambió la fisionomía del centro. 
Con los edificios de altura, sobre todo en la Gran Vía, se rompió por completo la escala del casco, y es poco lo que sabemos acerca de cómo los madrileños que no fueran escritores encajaron ese cambio tan brusco y tan brutal. Lo que sí sabemos es que hacia fines de los años veinte en adelante empezaron a proliferar las comparaciones con Nueva York en que, inevitablemente, la Gran Vía era Broadway. Esta meta era a todas luces inalcanzable, pero como aspiración llegó en los años de la Republica a formar parte del imaginario de no pocos madrileños. Hay en esto, además, un cierto desplazamiento de París, no en la práctica, porque los madrileños cuyo peculio daba para esas expansiones seguían acudiendo a la capital de Francia, mientras que eran pocos los que iban a Nueva York. James Fernández, profesor de la New York University, desde hace tiempo investiga a fondo la presencia española en Nueva York en esos años.

Estas construcciones de altura inauguraron una tipología arquitectónica nueva en Madrid: el edificio multifuncional cuyo modelo, a mi modo de ver, es el Coliseo. Ese edificio neoyorkino por excelencia, aunque en miniatura, tiene una peculiaridad, y es que, dadas sus características, se podía vivir en él sin salir nunca a la calle. En el Coliseo se produjo en 1935 una extraña y luctuosa historia entre dos personajes, uno completamente desconocido y otra perfectamente conocida. El desconocido se llamaba Tiburcio Fradeja Mardones, mientras que la archiconocida era nada menos que Conchita Piquer, que vivió largos años en la parte del Coliseo dedicada a vivienda. Fradeja era un madrileño de familia acomodada que se enamoró de una forma malsana de Conchita, acudió al Coliseo, donde alquiló un piso, y sometió a la tonadillera a un acoso despiadado durante meses. Mas al ver que sus pretensiones no podían de ninguna manera ser satisfechas, se desesperó y se tiró de un octavo piso.

Ahora bien, esto que yo acabo de contar no sucedió realmente. Se trata de una ficción de confección propia, lo mismo que el pobre de Fradeja, poeta apócrifo, ultraísta por más señas y no excesivamente bueno, que inventé hace cosa de veinte años. Pero he sacado a relucir esta historia folletinesca movido no por un impulso frívolo sino porque ejemplifica otro problema relacionado con la tarea de escribir una Historia de la cultura madrileña de esas décadas. Y es que de ese edificio multifuncional, el cine-teatro Coliseo, con sus viviendas y sus tiendas, construido a instancias del maestro Guerrero por dos arquitectos relativamente jóvenes pero de primera línea, Casto Fernández Shaw y Pedro 
Muguruza, y abierto a comienzos del año 1933, poseemos abundantes noticias que bien podrían servir de fundamento para que un historiador de la arquitectura escribiera una monografía. Pero al mismo tiempo es poco lo que sabemos de los que vivían y trabajaban en aquel edificio, es decir, que no lo conocemos desde dentro, y para hacer una historia de la cultura en que la mayoría de los madrileños tenga un cierto grado de protagonismo, es preciso que conozcamos las interioridades de este y de otros muchos edificios. De las casas de vecindad, por ejemplo, de las que seguimos sabiendo más bien poco.

En resumidas cuentas, si hemos de escribir una Historia de la cultura madrileña entre 1900 y 1936 que sea a la vez una "Historia de la cultura de los madrileños", nuestra obligación es enfocarla no solamente desde arriba, ni tampoco exclusivamente desde abajo, sino desde la totalidad de la sociedad real y existente de aquellas décadas prebélicas. El millón de madrileños de 1936 se la merece, y es la que nosotros necesitamos.

Muchas gracias por su atención. 